OLIVEIRA, A.C.B.; SEDIYAMA, M.A.N.; SEDIYAMA, T.; FINGER, F.L.; CRUZ, C.D. Variabilidade genética em batata-doce com base em marcadores isoenzimáticos. Horticultura Brasileira, Brasília, v. 20, n. 4, p. 576-582, dezembro 2002.

\title{
Variabilidade genética em batata-doce com base em marcadores isoenzimáticos
}

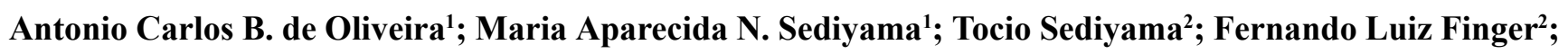 \\ Cosme Damião $\mathrm{Cruz}^{3}$ \\ ${ }^{1}$ EPAMIG-CTZM, C. Postal 216, 36.571-000 Viçosa-MG; E-mail: abaiao@mail.ufv.br. ${ }^{2}$ UFV, Dep ${ }^{\text {to }}$ fitotecnia; ${ }^{3}$ Dep $^{\text {to }}$ biologia vegetal, \\ 36.571-000 Viçosa-MG.
}

\begin{abstract}
RESUMO
A variabilidade genética de 55 clones de batata-doce, compreendendo cultivares comerciais e acessos obtidos de coletas, foi avaliada por meio de padrões isoenzimáticos, utilizando-se técnicas de análise multivariada. Cultivou-se uma planta por vaso, com 2 litros de capacidade, preenchido com terra, esterco e areia lavada na proporção de 3:2:1, com três repetições. As coletas das folhas e raízes novas para análises iniciaram-se aos 45 dias após o plantio. Foram utilizados, para folhas, os sistemas enzimáticos: GOT, $\alpha$ EST, $\beta E S T$, PGI, PGM e IDH e, para as raízes: PRX, $\alpha E S T, \beta E S T$, PGI, PGM e IDH. A combinação dos diferentes padrões enzimáticos e tecidos analisados possibilitou a discriminação individual de 32 dos 55 clones analisados. Os 23 clones restantes foram incluídos em sete grupos distintos, com base nos fenótipos isoenzimáticos exibidos. Os clones, dentro de cada um desses grupos, foram considerados materiais de mesmo genótipo, devido, também, às suas características morfológicas semelhantes. A aEST de raízes foi o sistema que apresentou maior número de bandas polimórficas, proporcionando a discriminação individual de 32 clones. O método de agrupamento de Tocher reuniu os 39 clones em nove grupos e, a análise pelo método das médias das distâncias, revelou a formação de onze grupos de similaridade. O clone 46 formou um grupo individual pelo método de Tocher e foi o mais divergente pelo método das médias das distâncias. Por apresentar boas características comerciais e produtivas, seria um dos clones eleitos para se iniciar programas de cruzamentos.
\end{abstract}

Palavras-chave: Ipomoea batatas, isoenzimas, eletroforese, análise multivariada.

\begin{abstract}
Genetic variability of sweet potato based on isozymes pattern

Genetic variability of 55 sweet potato clones, comprising commercial cultivars and collected accessions, was evaluated by using isozymes pattern and the genetic distance was estimated by multivariate analysis. Individual plants were grown in two liters pots filled with 3 parts of top soil: 2 parts of manure: 1 part of sand, totalizing three replicates. Harvest of young leaves and roots was initiated 45 days after planting. The isoenzymatic systems GOT, aEST, bEST, PGI, PGM and IDH for leaves and PRX, aEST, bEST, PGI, PGM and IDH for roots were estimated. The combination from the different enzymatic patterns and tissue analyzed enabled individual discrimination of 32 out of the 55 analysed clones. The 23 remaining clones were included in seven different groups, with base in the isoenzymatic phenotypes exhibited. The clones, within each of these groups, were considered materials of the same genotype, also on account of their similar morphological characteristics. The root aEST system showed the highest polymorphism, allowing the separation of 32 clones. The cluster Tocher's analysis joined the 39 clones in nine groups; the analysis by using the UPGMA method detected eleven groups of similarity. The clone called 46 formed an individual group when Tocher's analysis was applied and was the most divergent by the UPGMA method. Clone 46 with good commercial and production characteristics would be the primary choice for future breeding programs.
\end{abstract}

Keywords: Ipomoea batatas, isozymes, electrophoresis, multivariate analysis.

(Recebido para publicação em 18 de dezembro de 2000 e aceito em 16 de maio de 2002)

\begin{abstract}
$\mathrm{A}^{\mathrm{b}}$ batata-doce (Ipomoea batatas (L.) Lam.) é uma espécie autohexaplóide $(2 \mathrm{n}=6 \mathrm{X}=90)$, originária da América tropical e propagada, em sua maior parte, por via assexuada (Chen et al., 1992). O mecanismo de auto-incompatibilidade presente na espécie conduz à polinização cruzada e, portanto, a um alto grau de heterozigose. A polinização é, normalmente, feita por insetos e a autofecundação raramente ocorre. Há grande variabilidade fenotípica e genotípica nesta cultura, que se encontra disseminada por todo o território nacional. Quase todos os estados e municípios brasileiros possuem suas próprias cultivares, que, em muitos casos,
\end{abstract}

são mera duplicatas, pois é comum a ocorrência de cultivares iguais com nomes diferentes e vice-versa (Miranda, 1984; Murilo, 1990; Daros, 1999).

A caracterização adequada de cultivares de batata-doce, baseada em caracteres morfoagronômicos, implica na necessidade que os dados sejam provenientes da mesma época de colheita, do mesmo ambiente, da mesma densidade de plantio e que as plantas sejam cultivadas em condições propícias ao desenvolvimento adequado das mesmas, pois grande parte desses caracteres é altamente influenciada pelo ambiente (Huamán, 1996). Por essa razão, a utilização de ferramentas auxiliares, como as técnicas de eletroforese de isoenzimas, propicia aos melhoristas de plantas investigarem materiais genotípicos em nível próximo do DNA, pois os marcadores isoenzimáticos são produtos diretos da expressão gênica.

A análise isoenzimática além de ser técnica rápida, fidedigna e de custo relativamente baixo, possui várias aplicações no melhoramento vegetal, principalmente na identificação da variabilidade genética, possibilitando a caracterização de genótipos potenciais a serem utilizados nos programas de melhoramento (Matiello et al., 1998). Segundo Kennedy \& Tompson (1991), marcadores bioquímicos são mais pre- 
cisos na distinção de cultivares que as características morfológicas e as isoenzimas podem, ainda, ser utilizadas em estudos da variabilidade genética dentro de populações e o relacionamento genotípico entre clones. Conforme esses autores, os estudos isoenzimáticos em batata-doce são limitados, com poucas enzimas já investigadas. A maioria dos trabalhos realizados envolvem os sistemas enzimáticos esterase (Stegemann et al., 1992) e peroxidase (Chen et al., 1992).

A disponibilidade de técnicas eletroforéticas permite melhor entendimento dos níveis de distribuição da variabilidade genética nas populações. As isoenzimas são particularmente úteis, pois as populações são polimórficas em muitos locos, possibilitando a identificação de marcadores em qualquer espécie e são geralmente co-dominantes, de forma que, todas as classes genotípicas podem ser identificadas diretamente a partir de seu fenótipo isoenzimático (Robinson, 1998). Dias \& Kageyama (1991) relatam que o conhecimento do nível de variação genética e da distribuição permite direcionar estratégias de melhoramento, maximizar os ganhos genéticos e manejar as populações naturais visando a conservação genética.

O conhecimento da variabilidade genética disponível em um conjunto de genótipos é de grande importância em programas de melhoramento da batatadoce, sobretudo em procedimentos que envolvam hibridações, por evitar recombinações gênicas semelhantes, com conseqüente aumento da expectativa de expressão heterótica em híbridos e de ganhos genéticos em gerações segregantes. Além disso, permite evitar o plantio de formas genômicas idênticas ou semelhantes e o conseqüente estreitamento genético das cultivares (Daros, 1999).

Neste trabalho, propôs-se avaliar a variabilidade genética por intermédio dos polimorfismos isoenzimáticos em clones de batata-doce, com o propósito de identificá-los e detectar a ocorrência de possíveis duplicatas, e prover informações básicas da variabilidade dos clones para futuros programas de melhoramento da cultura.

\section{MATERIAL E MÉTODOS}

Os clones utilizados foram provenientes de várias regiões brasileiras e envolveram cultivares lançados por Instituições de pesquisa e acessos obtidos de coletas em feiras livres, mercados e áreas de produtores (Tabela 1). Cinco mudas de cada clone foram pré-enraizadas em areia lavada, por dez dias, e, em seguida, foram transferidas para vasos plásticos com capacidade para dois litros, contendo terra, esterco e areia lavada, na proporção de 3:2:1. Cultivouse uma planta por vaso, em casa-de-vegetação, utilizando-se nas análises, amostras de raízes e folhas novas de três plantas homogêneas de cada clone.

Foi realizada uma série de testes preliminares para adaptação da técnica de eletroforese horizontal em gel de amido não hidrolisado (amido comercial de milho "Maizena"). Nesta etapa, testaram-se as melhores combinações de sistemas enzimáticos, soluções extratoras, tampões gel/eletrodos, tipo de tecidos, concentração do gel e protocolos para revelação das bandas.

As análises iniciaram-se aos 45 dias após a transferência das plantas para os vasos, época em que havia disponibilidade suficiente de tecidos (folhas e raízes fibrosas). Foram testados os sistemas enzimáticos: aconitase (ACO; EC 4.2.1.3), álcool desidrogenase $(\mathrm{ADH}$; EC 1.1.1.1), a e b-Esterase (aEst, bEst; EC 3.1.1.2), fosfatase ácida (ACP; EC 3.1.3.2), glutamato desidrogenase (GDH; EC 1.4.1.3), glutamatooxaloacetato transaminase (GOT; EC 2.6.1.1), isocitrato desidrogenase (IDH; EC 1.1.1.42), leucina aminopeptidase (LAP; EC 3.4.11.1), malato desidrogenase (MDH; EC 1.1.1.37), fosfoglucose isomerase (PGI; EC 5.3.1.9), fosfoglucomutase (PGM; EC 5.4.2.2), peroxidase (PRX; EC 1.11.1.7) e xiquimato desidrogenase $(\mathrm{SKDH}$; 1.1.1.25).

Na maceração dos tecidos foram testadas as soluções extratoras 1 e 3, propostas por Alfenas et al. (1991), e esta última modificada pela adição de $0,1 \%$ de albumina. Folhas novas e extremidades de raízes fibrosas foram coletadas pela manhã, individualizadas em papel mata-borrão e acondicionadas em caixa de isopor, contendo gelo em escamas. No laboratório de Melhoramento de Hortaliças da Universidade Federal de Viçosa, procedeu-se à maceração dos tecidos em almofariz de porcelana previamente gelado. Na maceração foram testadas as proporções de 0,$5 ; 1,0 ; 1,5 \mathrm{e}$ 2,0 $\mathrm{ml}$ de solução extratora para cada mg de tecido. O macerado obtido foi coberto com gaze, visando a filtração do extrato, que foi absorvido em tiras de papel cromatográfico Whatman $3 \mathrm{MM}$, de 0,80 x 1,50 mm. Imediatamente após a absorção da solução, as tiras de papel foram enroladas em papel alumínio e mergulhadas em nitrogênio líquido sendo, em seguida, armazenadas em um "ultrafreezer" a $-80^{\circ} \mathrm{C}$, para posteriores análises eletroforéticas.

Os sistemas-tampão gel/eletrodo testados foram propostos por Shaw \& Prasad (1970), Soltis et al. (1983) e o sistema-tampão número 6 recomendado por estes últimos, com as seguintes modificações: no preparo do gel, utilizou-se uma mistura na proporção de 150 $\mathrm{ml}$ de tampão dos eletrodos e $850 \mathrm{ml}$ de tampão do gel, para os respectivos sistemas enzimáticos recomendados. $\mathrm{O}$ gel foi preparado em concentrações de amido que variaram de 10 a $15 \%$, com $3 \%$ de sacarose. $\mathrm{O}$ cozimento do gel foi realizado em forno microondas, agitandose vigorosamente a suspensão, inicialmente aos 45 segundos, e após esse intervalo, o tempo foi gradativamente reduzido, até atingir a fervura, seguindose agitações periódicas. O cozimento do gel foi completado com 4 a 5 minutos, dependendo do sistema-tampão utilizado.

Na corrida eletroforética foram utilizadas 10 amostras por gel, utilizandose três plantas por clone e um mínimo de três repetições para cada sistema enzimático. O corante azul de bromofenol foi inserido nas extremidades do gel, a fim de acompanhar a frente de migração durante a corrida. A eletroforese foi conduzida a $4^{\circ} \mathrm{C}$, sendo feita, inicialmente, uma pré-corrida de 30 minutos, para promover a liberação das enzimas contidas nas tiras de papel para o gel. Em seguida, as tiras de papel foram removidas e a corrida executada sob voltagem constante, tomando-se o cuidado para que a amperagem não ultrapassasse $45 \mathrm{~mA}$. A migração foi in- 
terrompida quando o corante atingiu a marca de $9,0 \mathrm{~cm}$ do ponto de aplicação da amostra. O gel foi fatiado e imerso em solução apropriada para revelação das bandas de cada sistema enzimático (Shaw \& Prasad, 1970; Soltis et al., 1983; Acquaah, 1992).

Após a secagem dos géis pelo método das placas de vidro (Alfenas et al., 1991), procedeu-se à leitura das bandas, atribuindo-se os escores 1 ou 0 , para presença ou ausência das bandas, respectivamente, para cada sistema enzimático e tecidos analisados. Os padrões isoenzimáticos obtidos foram utilizados para a identificação dos clones e confecção de uma matriz com os escores ( 1 ou 0 ) obtidos, sendo os clones marcados na linha e as bandas, na coluna. A matriz foi utilizada para obtenção do índice de similaridade genética de Jaccard $\left(\mathrm{S}_{\mathrm{J}}\right)$, proposto por Sneath \& Sokal, citados por Dias (1998). A partir do complemento aritmético desse índice, ou seja, 1-S , obteve-se a matriz de dissimilaridade genética entre os clones, que foi utilizada para avaliar a diversidade genética pelos métodos de agrupamentos de Tocher (Rao, 1952) e da média das distâncias (UPGMA). Também se procedeu à análise de escala multidimensional, conforme descrito por Dias (1998).

\section{RESULTADOS E DISCUSSÃO}

Os sistemas enzimáticos selecionados nos testes preliminares para análises foram: aEST, bEST, PGI e PGM para os tecidos foliares e radiculares, GOT para as amostras de folhas, e IDH e PRX para as raízes. Os sistemas enzimáticos $\mathrm{MDH}$ e SKDH, apesar de terem apresentado resolução satisfatória para extratos de raízes, foram eliminados das análises em razão da ausência de polimorfismo das enzimas, em todos os clones analisados, não contribuindo para a discriminação dos genótipos avaliados. O sistema GOT apresentou atividade baixa, evidenciada por bandas fracas no gel, em amostras de raízes, o mesmo ocorrendo com a PRX, em relação a amostras de folhas. Chen et al. (1992) também detectaram baixa atividade de peroxidases em folhas, em detrimento de alta atividade dessa enzima em raízes fibrosas de batata-doce. Os sistemas enzimáticos IDH, MDH, e SKDH não apresentaram resolução satisfatória em extratos foliares. Quanto aos sistemas ACO, ACP, ADH, GDH e LAP, estes não foram incluídos nas análises eletroforéticas definitivas, por não terem apresentado atividade e/ou resolução apreciável nas amostras de folhas e raízes. Todas as enzimas apresentaram apenas atividade anódica, com exceção da PRX, que apresentou bandas na região anódica e catódica.

As melhores resoluções dos padrões isoenzimáticos foram obtidas quando se empregaram, na maceração dos tecidos, $1,0 \mathrm{ml}$ da solução extratora 1 (Alfenas et al., 1991) para cada 1,0 mg de raízes e 1,5 ml da solução extratora 3 (Alfenas et al., 1991), modificada, para cada 1,0 $\mathrm{mg}$ de tecidos foliares. Cuidados redobrados devem ser tomados na maceração de tecidos foliares, pois mesmo com a utilização de substâncias que reduzem a reação dos compostos fenólicos com as enzimas, estes, quando descompartimentalizados, são rapidamente oxidados pela ação de fenoloxidases, muito ativas nesse tecido em batata-doce.

O sistema-tampão gel/eletrodos número 1 (Shaw \& Prasad, 1970) foi o que proporcionou as melhores resoluções para o sistema isoenzimático IDH. No padrão de bandas desta enzima, parece haver a formação de bandas "fantasmas" ou artefatos, gerados provavelmente pela degradação da amostra, o que não pôde ser contornado nas condições testadas. Efeito semelhante foi observado por Souza (2000) em trabalhos com umbuzeiro. Para as enzimas aEST, bEST, GOT, PGI, PGM e PRX as melhores resoluções foram alcançadas com a utilização do sistema-tampão proposto por Soltis et al. (1983) com modificações, que emprega $\mathrm{H}_{3} \mathrm{BO}_{3}-0,3 \mathrm{M}$ e $\mathrm{NaOH}-0,1 \mathrm{M}, \mathrm{pH} 8,6$, nos eletrodos e $150 \mathrm{ml}$ desse tampão, completado para 1,0 litro com o tampão Tris - $15,0 \mathrm{mM} \mathrm{e}$ ácido cítrico - 4,0 mM, pH 8,0, no preparo do gel. Este apresentou as melhores características físicas e resoluções, quando preparado com amido a $12 \%$.

Detectou-se polimorfismo interclones em todos os sistemas enzimáticos selecionados, possibilitan- do o emprego da técnica de análise isoenzimática na discriminação e no estudo da variabilidade genética entre os clones. Não foi observada ocorrência de polimorfismo intraclonal, o que facilitou a adoção dessa técnica na discriminação genotípica dos clones e, também, a interpretação dos resultados encontrados. Esses resultados são distintos daqueles obtidos por Sediyama et al. (1995), em trabalhos realizados com clones de couve e por Sales Filho (1991) e Borsoi Filho (1995), trabalhando com mandioca, que encontraram padrões isoenzimáticos distintos dentro de um mesmo clone ou cultivar, atribuindo esses resultados à ocorrência de mutação somática em determinado tecido vegetal; nos estudos com mandioca, e à complexidade multienzimática da peroxidase, nas avaliações realizadas nos clones de couve.

A combinação dos diferentes padrões isoenzimáticos de todas as enzimas avaliadas nos dois tipos de tecidos possibilitou a discriminação individual de 32 dos 55 clones analisados, conforme relacionados a seguir: clones número $1,2,3,4,5,6,7,13,15,16,17$, $18,23,24,26,28,29,30,31,32,35$, $36,37,38,41,42,43,44,46,48,49 \mathrm{e}$ 55 . Os 23 clones restantes formaram sete grupos distintos, que incluíram de dois a seis clones por grupo, com base nos fenótipos isoenzimáticos exibidos nas análises eletroforéticas de todos os sistemas enzimáticos avaliados em folhas e raízes (Tabela 2). Os clones dentro de cada um desses sete grupos (Tabela 2) foram considerados como materiais de mesmo genótipo (duplicatas), pois além de apresentarem mesmo fenótipo isoenzimático, exibiram, também, características morfológicas similares (Tabela 1).

A aEST de raízes foi a enzima que apresentou o maior número de padrões de bandeamento polimórficos, proporcionando a discriminação individual de 32 clones, enquanto IDH, em raízes, exibiu apenas dois padrões de bandeamento distintos (Tabela 3 ). Stegemann et al. (1992), concluíram que a eletroforese de a e bEST é eficiente para identificar cultivares de batata-doce e que a ocorrência de duplicatas nas coleções de germoplasma dessa espécie 
Tabela 1. Descrição e local de origem dos clones de batata-doce. Viçosa, EPAMIG, 2000.

\begin{tabular}{|c|c|c|c|c|}
\hline Clones* & Tipo de Lóbulo & Cor da Casca & Cor da Polpa & Local de Origem \\
\hline 1 & Profundos & Creme & Creme & Janaúba - MG \\
\hline 2 & Superficiais & Rosada & Amarela & Janaúba - MG \\
\hline 3 & Superficiais & Branca & Creme & Janaúba - MG \\
\hline 4 & Muito Superficiais & Roxa-escuro & Amarelo-pálido & Janaúba - MG \\
\hline 5 & Superficiais & Rosada & Amarelo-pálido & Janaúba - MG \\
\hline 6 & Superficiais & Branca & Creme & Janaúba - MG \\
\hline 7 & Muito Superficiais & Roxa & Creme-escuro & Janaúba - MG \\
\hline 8 & Muito Superficiais & Branca & Branca & Janaúba - MG \\
\hline 9 & Moderados & Rosada & Amarelo-pálido & Janaúba - MG \\
\hline 10 & Moderados & Rosada & Amarelo-pálido & Janaúba - MG \\
\hline 11 & Moderados & Rosada & Amarelo-pálido & Janaúba - MG \\
\hline 12 & Moderados & Rosada & Amarelo-pálido & Janaúba - MG \\
\hline 13 & Moderados & Amarelo-pálido & Branca & Janaúba - MG \\
\hline 14 & Moderados & Roxa & Creme-escuro & Janaúba - MG \\
\hline 15 & Muito Superficiais & Marrom-alaranjado & Alaranjado-pálido & Janaúba - MG \\
\hline 16 & Muito Superficiais & Roxa-escuro & Amarelo-escuro & Janaúba - MG \\
\hline 17 & Superficiais & Rosada & Amarelo-pálido & Janaúba - MG \\
\hline 18 & Muito Superficiais & Vinho & Pigmentada roxo & Janaúba - MG \\
\hline 19 & Moderados & Rosada & Amarelo-pálido & Viçosa - MG \\
\hline 20 & Moderados & Roxa & Creme-escuro & Viçosa - MG \\
\hline 21 & Moderados & Rosada & Amarelo-pálido & Viçosa - MG \\
\hline 22 & Moderados & Roxa & Creme-escuro & Viçosa - MG \\
\hline 23 & Superficiais & Branca & Creme & Bom Jardim de Minas - MG \\
\hline 24 & Superficiais & Branca & Creme-escuro & Bom Jardim de Minas - MG \\
\hline 25 & Profundos & Branca & Branca & Bom Jardim de Minas - MG \\
\hline 26 & Muito Superficiais & Branca & Creme & Lavras - MG \\
\hline 27 & Superficiais & Creme-escuro & Amarelo-pálido & Linhares - ES \\
\hline 28 & Moderados & Rosada & Creme & Oratórios - MG \\
\hline 29 & Moderados & Rosada & Branca & Gurupi - TO \\
\hline 30 & Superficiais & Creme-escuro & Amarelo-pálido & Gurupi - TO \\
\hline 31 & Superficiais & Rosada & Creme-escuro & Venda Nova do Imigrante - ES \\
\hline 32 & Profundos & Branca & Branca & Viçosa - MG \\
\hline 33 & Superficiais & Creme-escuro & Amarelo-pálido & Viçosa - MG \\
\hline 34 & Moderados & Rosada & Branca & Viçosa - MG \\
\hline 35 & Superficiais & Marrom-alaranjada & Amarelo-pálido & Manaus - AM \\
\hline 36 & Muito Superficiais & Branca & Creme-escuro & Santo Antonio da Platina - PR \\
\hline 37 & Superficiais & Rosada & Creme-escuro & Lond rina - PR \\
\hline 38 & Muito Superficiais & Amarelo-pálido & Creme-escuro & Holambra II - SP \\
\hline 39 & Moderados & Rosada & Branca & Vitória da.Conquista - BA \\
\hline 41 & Muito Superficiais & Rosada & Amarelo-pálido & Vitória da Conquista - BA \\
\hline 42 & Muito Superficiais & Branca & Branca & Vitória da Conquista - BA \\
\hline 43 & Profundos & Branca & Creme-escuro & Vitória da Conquista - BA \\
\hline 44 & Muito Superficiais & Vinho & Roxeada & Vitória da Conquista - BA \\
\hline 45 & Moderados & Roxa & Creme & Uberlândia - MG \\
\hline 46 & Moderados & Roxa-escuro & Creme & São José do Rio Preto - SP \\
\hline 47 & Muito Superficiais & Branca & Branca & São José do Rio Preto - SP \\
\hline 48 & Moderados & Roxa-escuro & Roxeada & Dourados - MS \\
\hline 49 & Muito Superficiais & Branca & Amarelo-escuro & Dourados - MS \\
\hline 50 & Profundos & Branca & Branca & Paula Cândido - MG \\
\hline 51 & Muito Superficiais & Branca & Branca & Mocambinho - MG \\
\hline 52 & Muito Superficiais & Branca & Branca & Mocambinho - MG \\
\hline 53 & Moderados & Roxa & Amarelo-pálido & Viçosa - MG \\
\hline 54 & Moderados & Roxa & Amarelo-pálido & Viçosa - MG \\
\hline 55 & Moderados & Roxa-avermelhado & Creme & Viçosa - MG \\
\hline 56 & Moderados & Creme-escuro & Amarelo-pálido & Viçosa-MG \\
\hline
\end{tabular}

*O clone número 40 não foi avaliado 


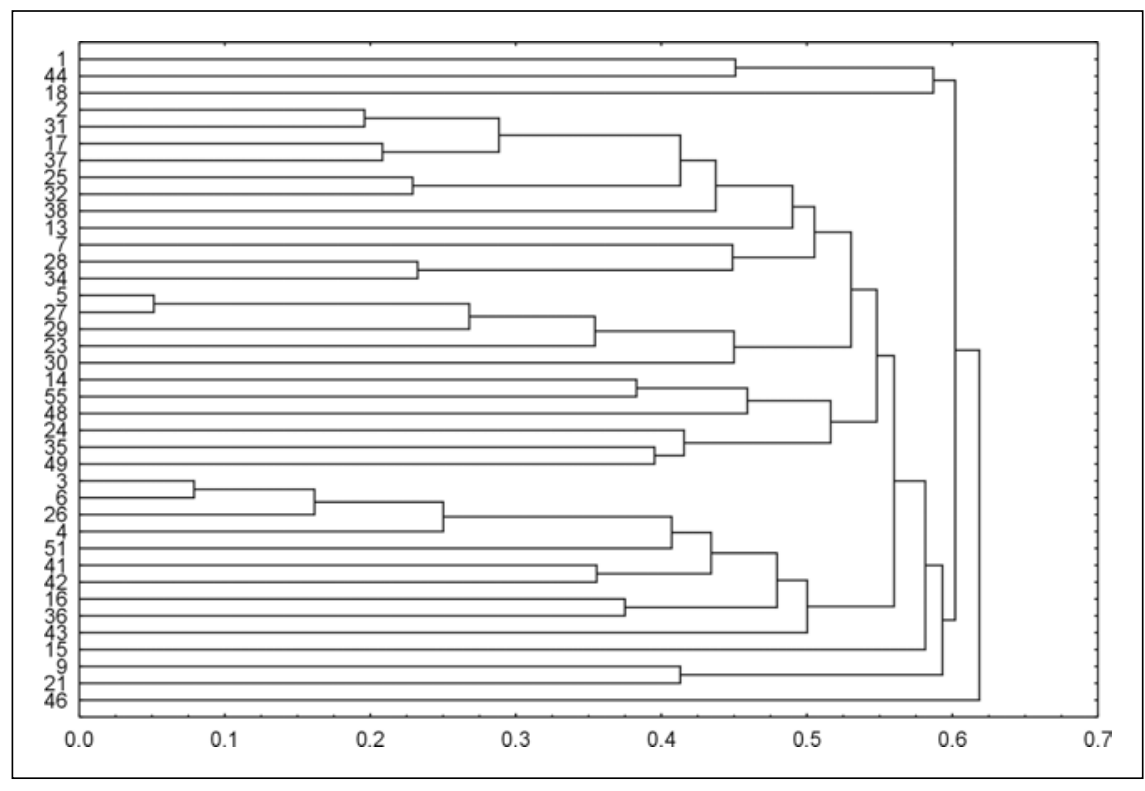

Figura 1. Análise de agrupamento pelo método das médias das distâncias (UPGMA) relativas a 39 clones de batata-doce, com base em 83 bandas isoenzimáticas, de acordo com a dissimilaridade do complemento aritmético do índice de Jaccard. Viçosa, EPAMIG, 2000.

Tabela 2. Agrupamento de clones de batata-doce que apresentaram o mesmo fenótipo isoenzimático nas análises de folhas e raízes. Viçosa, EPAMIG, 2000.

\begin{tabular}{cc}
\hline Fenótipo Isoenzimático & Clones \\
\hline A & $8,47,51,52$ \\
B & $9,10,11,12$ \\
C & $14,20,22,45,53,54$ \\
D & 19,21 \\
E & 25,50 \\
F & $27,33,56$ \\
G & 34,39 \\
\hline
\end{tabular}

*Clones dentro de um mesmo grupo foram considerados genotipicamente similares (duplicatas).

são comuns, devido às estratégias de amostragem adotadas. Matiello et al. (1998), também utilizando o sistema EST identificaram, individualmente, 28 genótipos de aveias hexaplóides, com base na ocorrência de treze bandas diferenciadas entre todos os genótipos avaliados.

Os 39 clones de batata-doce, considerados distintos pelas análises dos padrões isoenzimáticos, e as 83 bandas analisadas em todos os sistemas enzimáticos em tecidos foliares e radiculares, deram origem a uma matriz, com essas dimensões, a qual foi utilizada para se estudar a variabilidade genética desses clones, a partir dos agrupamentos formados. O método de agrupamento de Tocher reuniu os clones em nove grupos de similaridade, onde qua- tro grupos foram constituídos por apenas um clone e os demais grupos, por dois ou mais clones (Tabela 4). Segundo Cruz \& Regazzi (1997), o método de otimização de Tocher adota como critério que a média das medidas de dissimilaridade dentro de cada grupo deve ser menor que as distâncias médias entre quaisquer grupos. Assim, este método procura maximizar a distância intergrupos e minimizá-la dentro de cada grupo. Seguindo esse critério, os clones mais divergentes geneticamente são aqueles alocados em grupos distintos e, consequentemente, os clones mais similares são aqueles componentes de um mesmo grupo (Tabela 4).

Os métodos hierárquicos aglomerativos são de uso generalizado na análise de dados biológicos. Dentre eles, o método das médias das distâncias (UPGMA) é considerado por vários autores como um dos mais eficientes, como concluiu Dudley, citado por Dias (1998). Este método foi utilizado, com sucesso, para estudar a variabilidade genética através de polimorfismos isoenzimáticos em aveias hexaplóides (Matiello et al., 1998) e em Citrus spp. e Poncirus trifoliata (Novelli et al., 2000). A análise de agrupamento dos 39 clones de batata-doce, obtida por este método, revelou a formação de onze grupos (I a XI) de similaridade (Figura 1), nos quais os clones foram distribuídos da seguinte forma: I) 1 , 44; II) 18; III) 2, 31,17, 37, 25, 32, 38, 13; IV) 7, 28, 34; V) 5, 27, 29, 23, 30; VI) 14, 55, 48; VII) 24, 35, 49; (VIII) 3 , 6, 26, 4, 51, 41, 42, 16, 36, 43; IX) 15; X) 9, 21; e XI) 46 . O critério utilizado na formação destes grupos foi adotar o limite mínimo de $50 \%$ de similaridade entre os clones para que os mesmos fossem incluídos em um mesmo grupo. Este critério foi adotado com base no conhecimento prévio dos clones avaliados, por parte dos pesquisadores, visto que os grupos assim formados foram bastante coerentes com as características morfológicas apresentadas pelos genótipos estudados.

Dias (1998) menciona que este critério, utilizado para o estabelecimento de grupos de itens (acessos, clones, cultivares, etc.) a partir da análise de dendrogramas, é empregado por muitos pesquisadores na investigação do relacionamento entre itens, em pesquisas biológicas. No entanto, Cruz e Regazzi (1997) relatam que o estabelecimento dos grupos é feito de maneira subjetiva, tendo por base as mudanças acentuadas de níveis, que ocorrem no dendrograma, associadas ao conhecimento prévio que o pesquisador possui do material avaliado. O critério adotado neste trabalho, para a formação dos grupos de clones de batata-doce, pode, então, ser considerado satisfatório pelos autores desta pesquisa, pois os grupos formados foram bastante coerentes com o agrupamento pelo método de Tocher (Tabela 4), além de proporcionar individualização mais adequada dos clones com base em suas dissimilaridades genéticas. 
Tabela 3. Número de bandas e de padrões isoenzimáticos polimórficos, por sistema enzimático e por tipo de tecido analisado, em 55 clones de batata-doce. Viçosa, EPAMIG, 2000.

\begin{tabular}{cccc}
\hline Sistema Enzimático & Tipo de Tecido & $\begin{array}{c}\text { Número de Bandas } \\
\text { Analisadas }\end{array}$ & $\begin{array}{c}\text { Número de Padrões } \\
\text { Polimórficos }\end{array}$ \\
\hline EST & Raiz & 12 & 32 \\
EST & Folha & 10 & 27 \\
EST & Raiz & 7 & 23 \\
EST & Folha & 9 & 18 \\
GOT & Folha & 8 & 13 \\
PGI & Raiz & 9 & 11 \\
PGI & Folha & 9 & 9 \\
PGM & Raiz & 7 & 11 \\
PGM & Folha & 7 & 13 \\
IDH & Raiz & 2 & 2 \\
PRX & Raiz & 3 & 4 \\
\hline
\end{tabular}

Tabela 4. Agrupamento de 39 clones de batata-doce, pelo método de Tocher, com base na matriz de dissimilaridade do Complemento Aritmético do Índice de Jaccard, gerado a partir de dados isoenzimáticos de folhas e raízes. Viçosa, EPAMIG, 2000.

\begin{tabular}{|c|c|}
\hline Grupos & Clones \\
\hline I & $\begin{array}{l}5,27,29,31,2,23,17,37,24,32,38,25,21,41,28,34,48 \\
7,42,49\end{array}$ \\
\hline II & $3,6,26,4,51,16,36,43$ \\
\hline III & $14,55,35$ \\
\hline IV & 1,44 \\
\hline V & 13,15 \\
\hline VI & 46 \\
\hline VII & 9 \\
\hline VIII & 30 \\
\hline IX & 18 \\
\hline
\end{tabular}

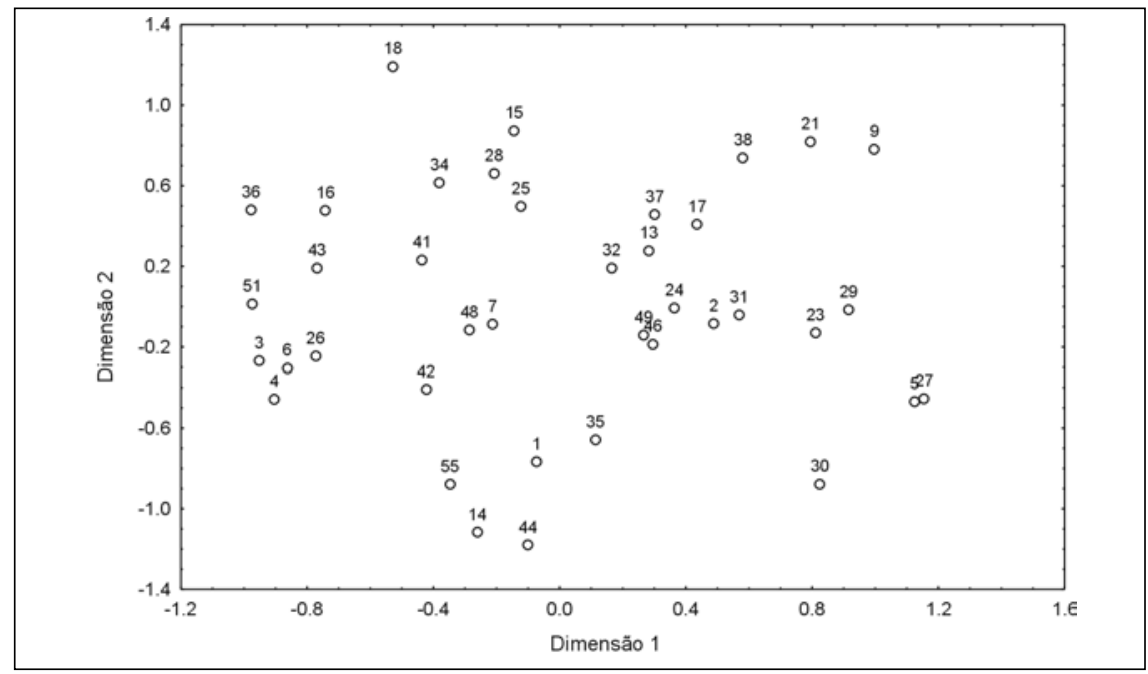

Figura 2. Dispersão de 39 clones de batata-doce por Análise de Escala Multidimensional, a partir da dissimilaridade do complemento aritmético do índice de Jaccard, com base em 83 bandas isoenzimáticas. Viçosa, EPAMIG, 2000.
No critério de escolha do método de agrupamento mais adequado, Bussab et al. (1990) recomendam que sejam aplicadas diferentes técnicas de agrupamento ao mesmo conjunto de dados e que a estrutura resultante da maioria deles seja aceita como a mais adequada. Essa recomendação evita que a classificação obtida seja um artefato da técnica, já que cada uma impõe determinada estrutura aos dados.

O agrupamento dos itens é importante para sumariar a informação contida na matriz de distâncias (Dias, 1998). Contudo, o agrupamento conduz à perda de informações em níveis de itens, restando apenas informações sobre grupos de itens similares. Por esse motivo, o estudo da variabilidade é implementado também e, por vezes, simultaneamente por técnicas que propiciem a recuperação da informação em nível de itens, a partir da representação gráfica em duas dimensões. A análise de escala multidimensinal (MDS) é uma técnica de redução de dimensionalidade, por produzir um gráfico espacial de baixa dimensão para uma configuração de itens.

A dispersão gráfica dos clones de batata-doce por meio dessa técnica encontra-se na Figura 2. A estatística estresse, que avalia o ajuste da matriz de coordenadas bidimensional à matriz de distâncias, apresentou valor igual a 1,17 , indicando que houve ajuste moderado a bom na transposição dos dados do espaço $n$-dimensional para o 
bidimensional, possibilitando a visualização dos clones em um plano cartesiano de duas coordenadas. Estes resultados podem ser de extrema utilidade para planejar cruzamentos entre clones ou grupo de clones, com a finalidade de se explorar a heterose produzida a partir desses cruzamentos e, ou iniciar um programa de seleção recorrente a partir de policruzamentos efetuados com os clones mais dissimilares geneticamente, que apresentem características comerciais desejáveis e bom desempenho per se.

O clone 46, por ter formado um grupo individual pelo método de Tocher e ter se mostrado como o mais divergente pelo método UPGMA e, em razão de suas boas características comerciais e produtivas, é um dos eleitos para se iniciar programas de cruzamentos, evitando-se a hibridação desse clone com os de números 49 e 24 , pois estes se apresentaram bastantes próximos ao clone 46, pela Análise de Escala Multidimensional (Figura 2).

A análise de polimorfismos isoenzimáticos de folhas e raízes de batata-doce foi eficaz na identificação de clones e na revelação da ocorrência de duplicatas em um conjunto de genótipos reunidos de várias localidades. Os marcadores isoenzimáticos foram úteis na avaliação da variabilidade genética entre clones de batata-doce, com o estabelecimento de grupos de similaridade por diferentes técnicas de agrupamento.

\section{AGRADECIMENTOS}

Os autores agradecem à FAPEMIG pelo financiamento desta pesquisa e pela concessão da bolsa Recém-Doutor, ao pesquisador Antonio Carlos Baião de Oliveira.

\section{LITERATURA CITADA}

ACQUAAH, G. Practical protein electrophoresis for genetic research. Oregon: Dioscorides Press, $1992.131 \mathrm{p}$

ALFENAS, A.C.; PETERS, I.; BRUNE, W.; PASSADOR, G.C. Eletroforese de proteinas e isoenzimas de fungos e essências florestais. Viçosa: UFV, 1991. 242 p.

BORSOI FILHO, J.L. Variabilidade isozimática e divergência genética de seis cultivares de mandioca (Manihot esculenta Crantz). Viçosa: UFV, 1995. 52 p. (Tese mestrado)

BUSSAB, W.O.; MIAZAKI, E.S.; ANDRADE, D.F. Introdução à análise de agrupamentos. São Paulo: IME/USP, 1990. 105 p.

CHEN, L.O.; LO, H.S.; CHEN, T.H.; LEE, L. Peroxidase zymograms of sweet potato (Ipomoea batatas (L.) Lam) grown under hydroponic culture. Botanical Bulletin of Academia Sinica, v. 33 , p. 247-252, 1992.

CRUZ, C.D.; REGAZZI, A.J. Modelos biométricos aplicados ao melhoramento genético. Viçosa: UFV, 1997. 390 p.

DAROS, M. Caracterização morfológica e estabilidade de produção de Ipomoea batatas em Campos dos Goytacazes, RJ. Campos dos Goytacazes: UENF, 1999. 67 p. (Tese mestrado).

DIAS, L.A.S. Análises multidimensionais. In: ALFENAS, A.C. ed. Eletroforese de isoenzimas e proteinas afins: fundamentos e aplicações em plantas e microorganismos. Viçosa: UFV, 1998, p. 401-475.

DIAS, L.A.S.; KAGEYAMA, P.Y. Variação genética em espécies arbóreas e conseqüências para o melhoramento florestal. Agrotropica, v. 3, p. 119127, 1991.

HUAMÁN, Z. Botânica, sistemática y morfologia de la planta de batata o camote. In: Manual de manejo de germoplasma de batata o camote (Ipomoea batatas). Lima, Peru: CIP, 1996. p. 116.

KENNEDY, L.S.; THOMPSON, P.G. Identification of sweetpotato cultivars using isozyme analysis. HortSciense, v. 26, n. 3, p. 300302, 1991.

MATIELLO, R.R.; BARBOSA NETO, J.F.; SERENO, M.J.C.M.; TADERKA, I.; PEGORARO, D.G. Variabilidade genética através de polimorfismos isoenzimáticos em aveias hexaplóides. Pesquisa Agropecuária Brasileira, Brasília, v. 33, n. 6, p. 913-918, 1998.
MIRANDA, J.E.C. Batata-doce: Evolução e melhoramento. Piracicaba: ESALQ/USP, 1984. 139 p. (Monografia).

MURILO, D.V. Cultivares de batata-doce. In: ENCONTRO DE PROFESSORES, PESQUISADORES E EXTENCIONISTAS DE OLERICULTURA DO RIO GRANDE DO NORTE, 4., 1990, Mossoró. Anais... Mossoró: ESAM, 1990. p. 27-29.

NOVELLI, V.M.; MACHADO, M.A.; LOPES, C.R. Isoenzymatic polymorphism in Citrus spp. and Poncirus trifoliata (L.) Raf. (Rutaceae). Genetics and Molecular Biology, v. 23, n. 1, p. 163-168, 2000.

RAO, C.R. Advanced statistical methods in biometric research. New York: John Wiley \& Sons, 1952. $390 \mathrm{p}$

ROBINSON, I.P. Aloenzimas na genética de populações de plantas. In: ALFENAS, A.C. ed. Eletroforese de isoenzimas e proteinas afins: fundamentos e aplicações em plantas e microorganismos. Viçosa: UFV, 1998, p. 329-380. SALES FILHO, J.B. Caracterização de cultivares de mandioca (Manihot esculenta Crantz) pela morfologia e padrões isozimáticos. Viçosa: UFV, 1991. 118 p. (Tese doutorado).

SEDIYAMA, M.A.N.; AMARAL JÚNIOR, A.T.; SILVA, D.J.H.; PICANÇO, M.C.; CRUZ, C.D. A study of biochemical markers of kale (Brassica oleraceae var. acephala) clones resistant to aphids (Brevicoryne brassicae). Revista Brasileira de Genética, Ribeirão Preto, v. 18, n. 3, p. 435-438, 1995.

SHAW, C.R.; PRASAD, R. Starch gel electrophoresis of enzymes: a compilation of recipes. Biochemical Genetics, v. 4, p. 297-320, 1970.

SOLTIS, D.E.; HAUFLER, C.H.; DARROW, D.C.; GASTONY, G.J. Starch gel electrophoresis of ferns: a compilation of grinding buffers, gel and electrode buffers, and staining schedules. American Fern Journal, v. 73, p. 9-27, 1983.

SOUZA, J.C. Variabilidade genética e sistema de cruzamentos em populações naturais de umbuzeiro (Spondias tuberosa Arr. Cam.). Viçosa: UFV, 2000. 86 p. (Tese doutorado).

STEGEMANN, H.; SHAH, A.A.; KRÖGERRECKLENFORT, E.; HAMZA, M.M. Sweet potato (Ipomoea batatas L.): genotype identification by electrophoretic methods and properties of their proteins. Plant Varieties and Seeds, v. 5, p. 83-91, 1992. 